\title{
Title: Social impacts of mining: changes within the local social landscape
}

\begin{abstract}
Understanding the social impacts at a community level triggered by mining operations is a challenging exercise. This paper reflects on a community's perceptions and interpretation of these impacts as well as on the qualitative changes in the local social landscape and their implications for a sustainable future. The findings are based on an exploratory research carried out in a small established settlement in Western Australia. Considered as an agricultural community for decades, Boddington currently hosts two mining operations. Even though mining has been carried out there for decades, the recent opening of a large-scale mining operation is triggering significant demographic changes which result in a structural and functional transformation of the local social environment. Two new phenomena, namely transiency and a dependency culture are identified. Maintaining existing levels of social and economic capital as well as mobilising the community's resources to capitalise on the opportunities associated with mining, are identified as key challenges for the settlement's sustainability.
\end{abstract}

Key words: transiency, dependency, social sustainability, mining, social impact, Boddington 


\section{Introduction}

Social and economic development in Australia has been marked by mining since the gold rushes from the mid-19 ${ }^{\text {th }}$ century (Kay et al., 2012). In Western Australia (WA), the discovery of alluvial gold in Coolgardie (1892) and Kalgoorlie (1893) caused a massive population increase and generated considerable wealth. Ever since the WA economy has been highly dependent on the resources sector. In the last decade, it experienced a phenomenal growth. In 2010-2011 the mineral and petroleum industry of WA, with its large and extremely diversified commodity base, reached a record high of $\$ 101.2$ billion (Government of Western Australia, 2011; Tonts et al., 2011). The State currently has 513 commercial mineral projects, encompassing 893 operating mine sites and producing over 50 different mineral resources (Government of Western Australia, 2011). Among those, gold mining continues to be of major importance and is the fourth largest commodity sector (following iron ore, crude oil and LNG).

In Australia, and particularly Western Australia, the mining industry cannot satisfy its requirements with local employees and depends heavily on non-resident workforce (Kay et al., 2012). The scale of mining operations, the location of the ore bodies and the concentration of the Australian population predominantly within large metropolitan areas prevent mining from relying on local labour. Company towns, where a mining company is responsible for building or substantially financing local community infrastructure, the hit of the 1970s, are now part of history. Nowadays the industry's preference is to be in already existing communities and if this is not possible, to construct temporary mining camps to accommodate for its labour requirements (McKenzie, 2011). They allow for Fly-in/Fly-out (FIFO) or Drive-in/Drive-out (DIDO) work practices, where people commute between work and home on a roster basis.

These new operating practices change the life and social fabrics of existing communities. The intensive resource extraction often requires large numbers of employees dwarfing the size of the local population. This creates new phenomena and social dynamics that completely change not only the nature of the mining operations but also transform the existing communities. By focusing on a particular case study, this paper reflects on the community's perceptions and interpretation of the social impacts of mining and explores the qualitative changes occurring in the local social landscape within an already established Western Australian community. Two mining operations - a large-scale gold mine (which re-opened in 
2010) and a small-scale bauxite mine (in operation for more than three decades) are currently active in the vicinity of Boddington. How is mining, and particularly the more recent largescale operation, changing the community? Mining is often seen as a catalyst for change, but what exactly are these changes? Are they contributing towards community's social sustainability? These are some of the questions that we address through the Boddington case study.

\section{Background}

The analysis of the social impacts of mining is not a new area of academic interest and the Australian booming resource sector influenced a significant research interest in recent years. The bulk of the studies focus on the pressure generated by mining on service provision, infrastructure and housing availability (MacKenzie et al., 2008; Lockie et al., 2009; Rolfe et al., 2007) and on the socio-economic wellbeing of the affected communities (Hajkowicz et al., 2011; Lawrie et al., 2011; Tonts et al., 2011). A further area of interest is the increasing reliance of mining companies operating in Australia on non-residential workforce covering issues such as employee turnover and FIFO arrangements (Beach et al., 2003; McKenzie, 2011; O’Connor \& Kershaw, 1999; Storey, 2001). The link between rural communities and resource development, particularly in the mining states of Queensland and Western Australia is another significant area of research (McKenzie, 2009; Petkova et al., 2009; Carrington and Pereira, 2011; Lockie et al., 2009; Rolfe et al., 2007; Stehlik et al., 2011).

Specific sensitive issues identified include implications for indigenous people (Howitt, 2001; O'Faircheallaigh, 2009) and distress to existing local communities, such as for example the influx of predominantly male population (Lozeva \& Marinova, 2010). The lack of facilities and pressure on infrastructure caused by mining impact on the capacity of other local employers to attract and retain employees and thus hinder the development of the local business environment (Lockie et al., 2009; Tonts, 2010).

Despite these challenges, there are also many benefits for existing communities. Lawrie et al. (2011) argue that the rapid expansion of the economy in resource boom towns leads to improved socio-economic conditions and reduction in welfare dependence.

It is too simplistic to see the impacts of mining as black or white. What is important is to understand the qualitative changes in the local social landscape triggered by the industry as they have social sustainability implications. From a sustainability perspective there is a need 
to explore the dynamics of societal changes which involve not only transformations in the natural environment but also social, economic and political processes (Dempsey, Bramley, Power, \& Brown, 2011).

Defined as a process and a goal, social sustainability is a social construct related to different forms of social capital (both positive and negative), incorporating social mobility and cohesion, solidarity and tolerance and has long-term goals (McKenzie, 2004; Barron \& Gauntlett, 2002; Dempsey et al., 2011). Social sustainability is also the foundation for diverse development paths depending on particular cultural, economic, political and/or ecological circumstances. Becker et al. (1997, p.19) argue that "sustainability should not refer to the conservation of specific structures or to static qualities of societies or the natural environment, but, rather, should refer to stabilized and preserved patterns within socialecological transformations". In other words, sustainability offers a possibility for a conceptual shift from categories of remaining and preservation to categories of change and transformation (Becker, 1997). This is particularly important for understanding the role of mining.

This paper aims to add to the existing body of knowledge surrounding the social impacts of mining by examining a particular case study in Western Australia, namely Boddington.

\section{Boddington}

The Shire of Boddington is located in the Peel region of Western Australia, $130 \mathrm{~km}$ southeast of the State's capital Perth. It covers around a dozen different towns and localities, the largest of which is the town of Boddington. Within a radius of $150 \mathrm{~km}$ around the shire are situated other key regional centres and towns, such as Mandurah, Bunbury and Collie (see table 1 and figure 1).

Table 1. Regional context

Population size, 2011

Distance from Boddington

\begin{tabular}{lcc}
\hline Perth & $1,728,867$ & $130 \mathrm{~km}$ \\
Bunbury & 31,348 & $170 \mathrm{~km}$ \\
Mandurah & 69,903 & $92 \mathrm{~km}$ \\
Collie & 9,127 & $115 \mathrm{~km}$ \\
Boddington & 2226 & $0 \mathrm{~km}$
\end{tabular}

Source: ABS 2012 


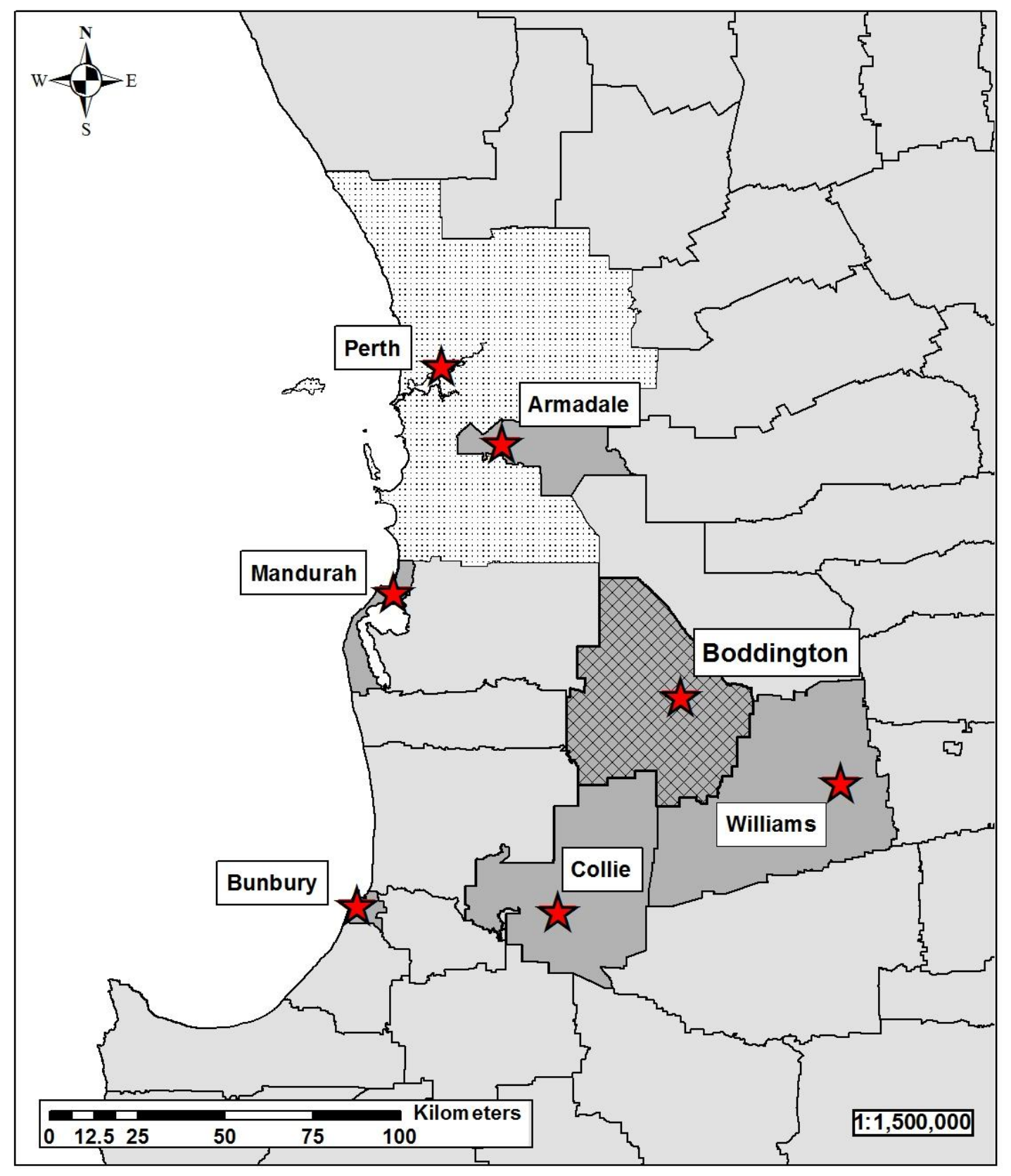

Figure 1. Selected Western Australian locations 
Gazetted in 1912 and established originally as an agricultural settlement, the town experienced periods of rise and decline associated with timber and mining activities. Currently there are two operational mines adjacent to Boddington: a small-scale bauxite mine active since the late 1970s, and a large-scale gold mine which first commenced in the mid1980s, ceased operation in 2001, and re-opened at a significantly larger scale in mid-2010. As of July 2011, the gold mine's total workforce numbers 1457 people of whom 943 are directly employed by the company and 485 by contractors (see table 2). Only 199 people from the entire workforce are local residents living within a $50 \mathrm{~km}$ radius of the mine, of whom 157 (or $10 \%$ ) reside in the town of Boddington.

Table 2. Boddington gold mine's workforce (2009-2011)

\begin{tabular}{lllll} 
Workforce & $\mathbf{2 0 0 9}$ & $\mathbf{2 0 1 0}$ & $\mathbf{Q 2 , 2 0 1 1}$ & July, 2011 \\
\hline Men & 497 & 655 & 795 & 797 \\
Women & 98 & 115 & 148 & 150 \\
Residential & 119 & 170 & 187 & 199 \\
Indigenous & 33 & 40 & 45 & 55 \\
Apprentices & 11 & 12 & 16 & 17 \\
Trainees & 10 & 5 & 7 & 27 \\
Contractors & 349 & 392 & 485 & 510 \\
Total & 944 & 1162 & 1428 & 1457 \\
Source: Compiled from company data. & &
\end{tabular}

The presence of Boddington is no longer defined by its agricultural history but is largely shaped by the mining industry. Mining has been a significant component in the area in the last thirty years or so, but more recently the large-scale operation drastically changed the social landscape as indicated by this case study research. 


\section{Methodology}

In order to investigate the links between the social impacts of mining and social sustainability, an exploratory approach was chosen, combining mixed methods techniques. In social sciences, exploration is a broad-ranging, purposive, systematic undertaking designed to maximise the description and understanding of an area of social life (Stebbins, 2001, p. 3). Exploratory studies are quite common when a researcher wants to gain a better understanding of the problem, breaking the broader problem into smaller well-defined sub-problems. Within the exploratory research the studied phenomenon is not approached according to a set formula, but the researcher adopts methods according to the nature and the setting in which the phenomenon is situated.

The adopted methodological approach uses a combination of qualitative and quantitative methods in a single study (Tashakkori \& Teddlie, 2003). A Human Research Ethics permit was obtained from Curtin University's Human Research Ethics Committee according to the Australian Code for the Responsible Conduct of Research and the approved ethical process was followed throughout the research.

The following research tools (Petrova, 2012) were used to collect information about the case study:

- A semi-structured community survey, carried out in November-December 2010, using a convenience sampling technique (Gravetter \& Forzano, 2008). Based on convenient and available access to respondents, convenience samples are widely used in exploratory research in the applied social sciences, because they are pragmatic, least time consuming and do not require a lot of resources (Gravetter \& Forzano, 2008). Despite the fact that convenience samples are not considered to be representative, the participants in this case were randomly recruited at different public community events. Only people who reside in Boddington were targeted as participants and a total of 56 people completed the self-administered questionnaire.

- Interviews with local government and company representatives as well as local opinion leaders, conducted in November 2010 - September 2011. Fourteen such interviews were carried out. 
- Australian Bureau of Statistics (ABS) data, including the 2001, 2006 and 2011 Australia's Population and Housing Censuses and other relevant publications, such as Community Profiles and time series.

- Other relevant documents and on-line materials, such as local development strategies and social and needs impact assessments carried out by both industry and local government.

A thorough analysis of the secondary data sources allowed for specific themes within the area of interest to be identified and located within existing theoretical frameworks. The questions in the community survey and interviews aimed at exploring this further by focussing on the impacts of mining on the specific local social landscape. They provided the empirical data around the themes described below. The survey data was processed with SPSS20. The data from the open ended-questions and interviews was qualitatively analysed in the search for common threads.

The data analysis allowed for new concepts to emerge. The sections to follow describe the recent changes in the social landscape of Boddington, covering demographic trends, social and cultural transformations.

\section{Population changes as a result of mining}

Historically Boddington was predominantly an agricultural settlement. Mineral deposits in the area were first discovered in 1957, however it was not until 1979 when mining activities started with the development of the bauxite reserve. After the decline of the timber industry in the 1960s, the shire population lost $40 \%$ of its residents over a five-year period (Boddington-Ranford Townsite Strategy, 2010). Over the next twenty years, the population size of the shire plateaued around 700 people (see Figure 2). The numbers started to pick up after the discovery of the gold deposit with mining commencing in 1987. Between 1986 and 1996, when the gold mine was in full operation, a significant population growth of more than $60 \%$ occurred (Boddington-Ranford Townsite Strategy, 2010). However, in the late 1980s and during the 1990s, wool prices dropped and economic returns from broad-acre cropping were variable. Many young people left and family farming was no longer an attractive livelihood (Tonts, 2010; McKenzie, 2010). Between 1996 and 2001, the shire registered a 7.6\% population decrease from 1516 to 1407 (Boddington-Ranford Townsite Strategy, 2010). 
The Australian Bureau of Statistics (ABS, 2011) data shows that after the 2001 closure of the gold mine the shire did not experience a serious population loss with numbers remaining stable. However, there were changes in the population structure. Between 2001 and 2006 the median age of the shire population increased from 33 to 39 and the share of people older than 45 increased by more than $10 \%$. The 2006 data reveals a reduction in the share of residents within the 25-45 age bracket who seemed to have walked away after the closure of the gold mine (figure 2). During that time Boddington begun to attract more retirees who were looking for a quiet place.

A significant change occurred in 2010, when the gold mine was re-opened and brought into a production phase. The population size of the Boddington shire almost doubled between 2006 and 2011 (figure 2) from 1379 to 2226 with a further $61 \%$ added to its residents. The main influx of people occurred in 2011 (ABS, 2012) (figure 2).

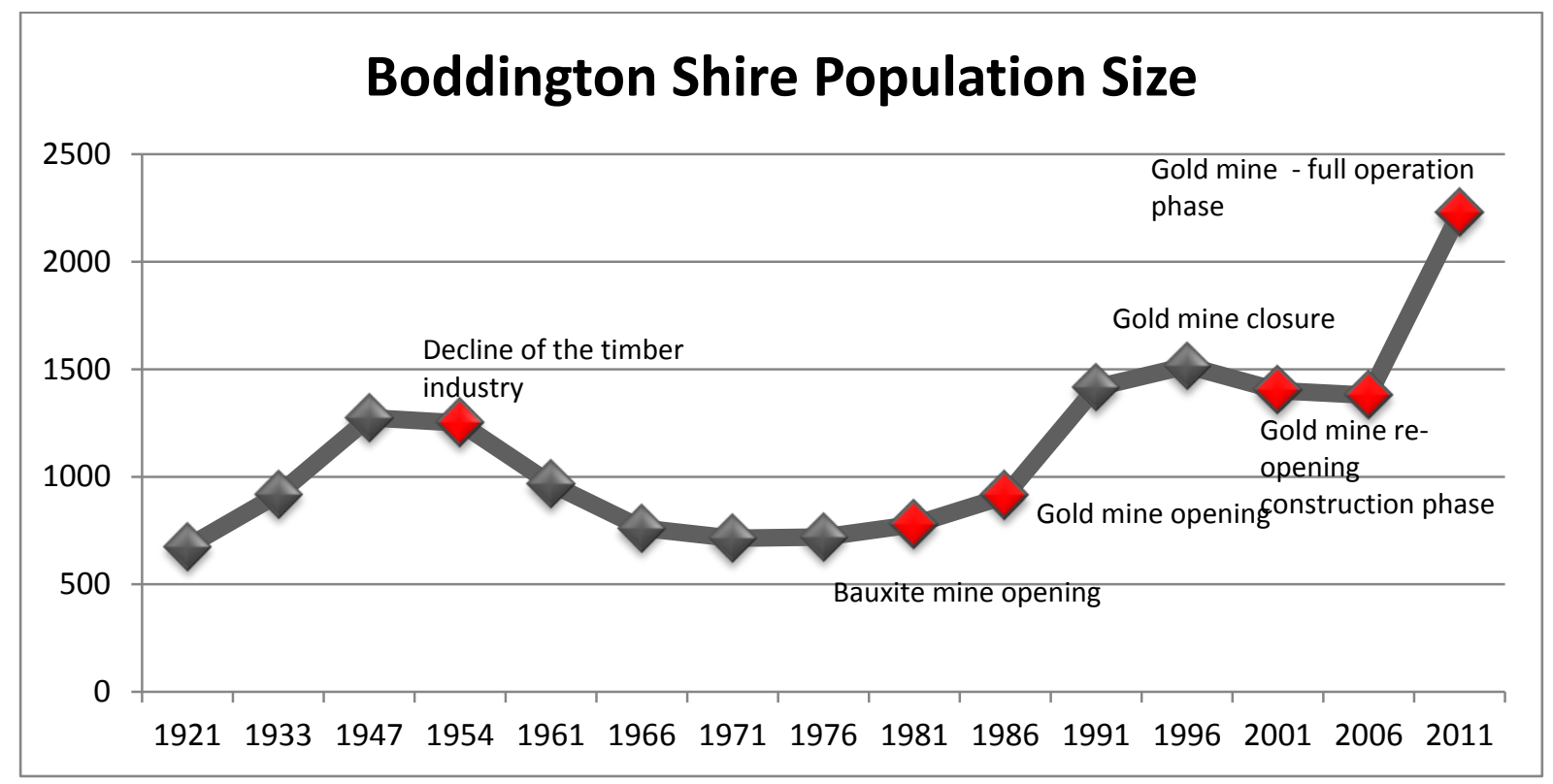

Figure 2 Population trends: Boddington

Source: ABS, 2012a and b

In the last ten years, the shire of Boddington had a relatively young population with around 35-37\% aged below 30 and 67\% below 50 (see figure 3). Until 2010, men slightly outnumbered women, but this changed drastically in 2011. The number of male residents almost doubled, with biggest influx being of young single men aged 25-34, and men currently comprise $62 \%$ of the shire's population. 


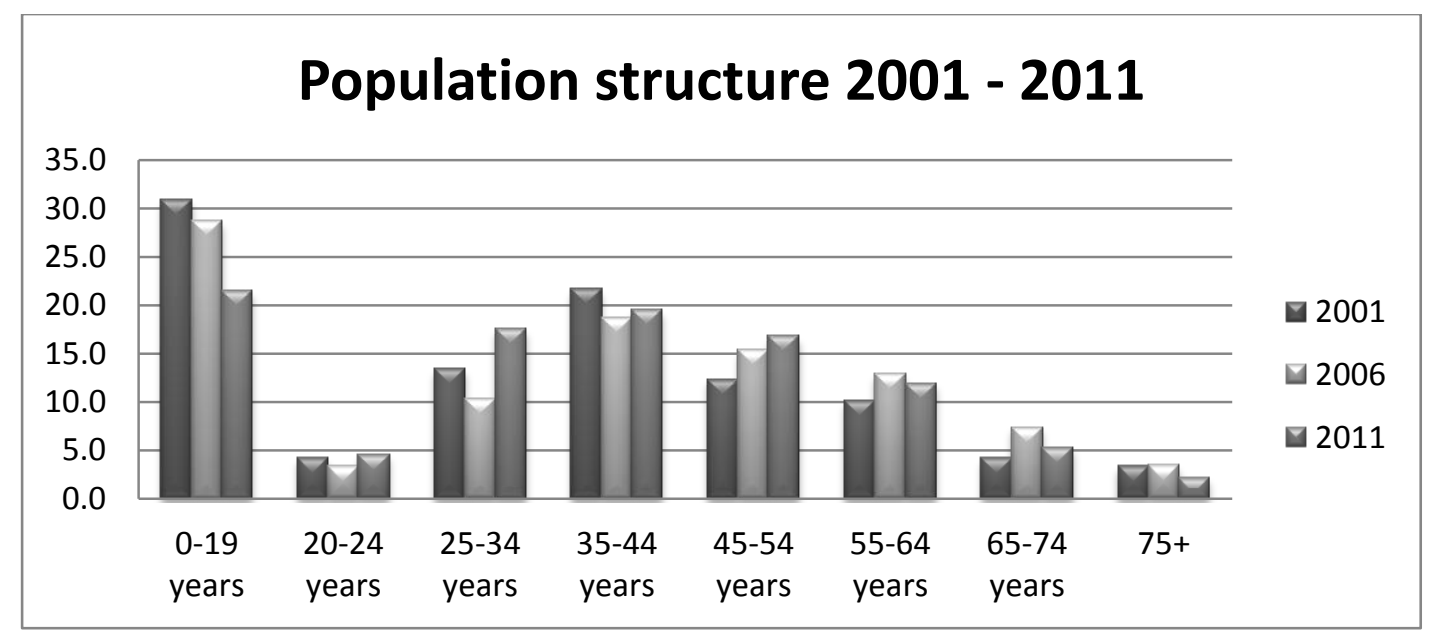

Figure 3. Population structure

Source: ABS, 2012a and b

According to the Boddington town strategy (Boddington-Ranford Townsite Strategy, 2010), it is expected the township population to increase to 2100 within the next five years and double by 2031. What is already demonstrated in this mining boom town is that its population is becoming very mobile.

\section{Mobile population}

The world today is characterised by a lot higher population mobility than even a decade ago and mining is contributing to this trend within Australia. The Australian population is one of the most mobile populations in the world (Department of Immigration and Citizenship, 2011). Mobility is a function of push and pull factors which operate differently across the country. A 2011 Department of Immigration and Citizenship (2011, p.15) report shows that between 2001 and 2006, about 40\% of the population aged 5 and over changed their permanent place of residence for a variety of reasons, including employment, housing needs, stage of life cycle such as marriage and other types of household formation, and retirement.

The nature of the mining industry, which is location bound, pre-determines the high geographic mobility of its workforce. Hence it is not surprising that mining is the sector with the highest rate of job mobility with $21 \%$ of its workforce changing jobs within a year compared to the national average of $9 \%$ (ABS, 2010). 
Table 3. Place of usual residence

2006

2011

$\begin{array}{ccccc} & \begin{array}{c}\text { Same address as 1 } \\ \text { year ago }\end{array} & \begin{array}{c}\text { Same address } \\ \text { as 5 years ago }\end{array} & \begin{array}{c}\text { Same address as } \\ 1 \text { year ago }\end{array} & \begin{array}{c}\text { Same address as 5 } \\ \text { years ago }\end{array} \\ \text { Boddington } & 76 \% & 45 \% & 60 \% & 33 \% \\ \text { Western } & 75 \% & 48 \% & 77 \% & 50 \%\end{array}$

Source: ABS 2012

The significant in-migration resulting from the vast employment opportunities associated with the large-scale mine in Boddington attracts a highly mobile population (see table 3 ). In 2011 , only $33 \%$ of the shire's population resided at the same address as five years earlier compared to 50\% for WA. The respective 2006 figures were $45 \%$ for Boddington compared to $48 \%$ for WA. While the 2006 figure for the shire was comparable to the State's mobility, in 2011 Boddington's population had a 17\% higher mobility rate than that for WA (see table $3)$.

Mining however also influences out-migration, something statistics do not always capture. For example, its effects on the property market can push people away from the town:

"Some people remained employed but sold up and went to the coast where properties were cheaper and they had money left over to pay off the mortgage. They now commute."(local informant)

"There is a serious shortage for housing, rents are as high as in Perth but the accommodation quality is not as good as there. When the mine first stopped in 2001, prices dropped significantly. Those who bought houses at that time, now managed to sell the properties at a very high price and buy new houses at the coast; these people still keep their jobs with mining in the area and commute to work every day." (local informant)

Another push factor for out-migration is the pressure on service provision. As no new educational facilities were added since the recommencement of the large-scale mine, some people have decided to commute from Perth, Mandurah and Bunbury in order to provide better educational opportunities for their families.

\section{Transient population}

Along with a highly mobile population resource-based communities appear to attract another category of people, namely a transient population. This category comprises of people who 
move frequently from place to place for a relatively short period of time following job opportunities. These people concentrate entirely on their jobs and their life revolves around employment, including locally based recreational activities. Participants in the study believed that these transient workers do not establish meaningful relations with the local community and do not participate in community life:

"There is a little bit of a distance between locals and newcomers, they do not socialise together and do not use the same networks." (local informant)

This causes social dilution within the community as newcomers and locals do not use the same social networks. Some Boddington locals are of the opinion that 'outsiders' impact negatively on the town's existing culture. The 'outsiders' have been described as "greedy" people who are "taking money away", "getting jobs" and "do not care about the town".

Mobile labour force, employee turnover and high demand for workers typical for large-scale operations, as in the case of Boddington, attract transient populations. We argue that there is a difference between being mobile and being transient. Employment is only one of the factors affecting population mobility while the culture associated with the transient population emerges as a new social phenomenon, namely transiency. It is a function of three interrelated phenomena - the nature of the mining industry, population mobility and transient workforce:

The location of mining operations and their lifecycle pre-determine the high geographic mobility of this industry's employees. Population mobility is simply the physical movement of people while transiency is associated mainly with the culture. The transient workforce is facilitated by the existence of a mining camp and the rostered work patterns typical for mining. In general, ABS statistics (e.g. table 3), do not report on transient population marginalising this phenomenon.

In the case of Boddington's large-scale mining operations, the transient population can be estimated based on the company's data (see table 2) to be $79 \%$ of all employees. The mining camp located $2 \mathrm{~km}$ outside the town covers an area of approximately $292,400 \mathrm{~m}^{2}$ and has the capacity to accommodate up to 2400 employees. It offers full services, including a canteen and dining room, gym, laundry facilities, entertainment rooms and hairdressing services. The usual FIFO and DIDO work roster is 8 on 6 off (i.e. 8 working and 6 non-working days). 
Through the Boddington case study, transiency was identified as a factor impacting on the normal functioning of the local social landscape by: (1) causing imbalance within the local population structure and (2) contributing to lower social capital. According to Beach et al. (2003, p. 4), when populations are unstable, as is the case with a transient labour force "it is much more difficult to build and maintain a sense of community and to sustain activities such as clubs and associations, which contribute positively to the social life of the community".

These demographic changes, namely population increase and transiency, are likely to continue to impact on Boddington's community life and its sustainability.

\section{Social impacts of mining}

It is relatively easier to describe and to a certain degree explain the demographic picture of Boddington than it is to understand the impact the large-scale mining has on the local community. Mining appears responsible for the high levels of pressure on the forms of local capital (social and economic). These are issues that cannot be simply resolved by the industry itself through its social impact management plans or corporate social responsibility. They require the community to acknowledge this, take ownership and become an active agent of change in order to build its resilience and long-term sustainability.

\section{Social capital}

The sustainability of a community is considered to be its ability to sustain and reproduce itself at an acceptable level of functioning (Dempsey et al., 2011). This is normally associated with 'social capital' and 'social cohesion' as concepts that encompass social networks, norms of reciprocity and features of social organisation (Coleman, 1988). Social capital also contributes to strong, fair and just societies (Lister, 2000). Distinct from the concept of human capital (which relates to the ability of a labour force to produce economic value), social capital describes the ability of community to achieve a common goal and maintain its normal functioning (Putnam, 2001). To assess the social capital in Boddington we considered the levels of trust, social organisation, networks and groups and voluntarism, and how these are changing over time.

Rapid population changes and associated increases in the number of unacquainted, unfamiliar residents may contribute to a decline in the trust in others in areas affected by boom growth 
(Freudenburg, 1986). General levels of trust are believed to be lower during periods of mining boom and higher during periods of greater population stability (Freudenburg, 1986). The community survey gauged the level of trust a couple of months after the large-scale mine transitioned from construction to operation. Almost half of the participants reported that the level of trust within the community remained unchanged after the re-commencement of the large-scale mine, but another $33 \%$ were of the opinion that this indicator had worsened. Specifically, the majority of the respondents believed that people within the community care about its general wellbeing rather than individual welfare; however a third thought the opposite to be the case.

Almost two thirds (namely $64 \%$ ) of the respondents considered Boddington to be a good place to raise children; but many noted that it is a perfect place for children and not for teenagers. The lack of educational opportunities as well as the limited entertainment activities for the youth were described as another reason for families with high-school aged children to leave the community. Availability of appropriate schooling has always been a problem for mining towns in Western Australia. The majority of the regional local schools do not offer university entry exams and this is a turning point for parents deciding whether to stay or leave a particular regional area (Forsey, 2011).

At 30, the 2010 number of active community groups and organisations in the town was relatively high. According to ABS 2006 census data, Boddington residents rank one of the top in WA mining communities according to the share of population engaged in voluntary work: $31 \%$ of the locals contribute voluntary work, compared to the $25 \%$ State average. However, in 2011 and after the re-opening of the large-scale mine this percentage was down to $20 \%$. Possible reasons for the change are the shire's expanding population with changing structure, decrease in the amount of free time and the long shift working hours:

“...Our town was going great before the mine, shift workers do not help local sporting bodies at all." (local informant)

"Some people from the mines do get involved in community activities but 12 hours shifts make it difficult to commit on a regular basis."(local informant) 
However, the large number of active community groups indicates a vibrant and socially resilient community. Even though the community has already experienced industry rise and decline cycles, it has never been exposed to such dramatic changes. It is evident that social cohesiveness and inclusion, interactions and participation in community life are currently in a process of transformation.

To cope with the rapidly emerging social changes, community members are trying to maintain the existing community spirit and are employing various initiatives to adapt to the new environment. The mothers' groups for example play an important role in integrating and providing support to the newly arrived families. This goes beyond their initial function and turns them into a valuable self-sustained social network. They actively apply strategies for sharing resources in helping each other compensating for the lack of baby-sitters. Some interviewees were also concerned about the provision of childcare services as they are not designed to suit full-time working mothers.

In essence, Boddington is a community with a very strong base of existing social cohesion. However, there is indication about recent decline in social capital, such as decrease in voluntary work within the community, participation in community groups and sport events. This signals that the social environment has started to transform.

\section{Economic capital}

Changes in economic capital can be represented with the level of business activities within the community and how mining affects them. According to Bourdieu (1986), economic capital can be immediately and directly convertible into money and is institutionalised within the local environment.

The participants acknowledged that mining contributes to the development of the local business environment; however, concerns were raised that as the population increases, retail outlets are expected to serve larger numbers of customers. Currently, retail opportunities are limited with only a few operational shops. Instead of shops popping up like mushrooms, a reduction in the number of local shops was observed and the lack of competition drives prices up, making local retailers uncompetitive. Businesses other than mining find it difficult to find and retain employees. Sectors, such as retail, hospitality and tourism, have to compete with the higher salaries, working conditions and benefit packages provided by mining, which 
makes other jobs unattractive and incompatible. Scarce human resources is pointed out as one of the reasons for the high turnover of local businesses:

"Small business owners find it hard to retain and hold employees" (local informant)

"It is very hard for local businesses to find staff. There are vacancies at the local super market, which cannot be filled since months. Several local hospitality businesses that were recently opened because of the mine had to close, because of the lack of staff." (local informant)

"As a project manager for a contracting company in the mining industry, one of the biggest challenges is to maintain a level of good employees who are committed to the task. (local resident)

This forces local people to look for other options to satisfy basic needs. The lack of local outlets brought into town a new way in daily shopping through online food shopping offered locally. Deliveries to town are executed once a week at reasonably cheaper prices, which additionally undermines local retailers. The proximity to Perth and other regional centres (Bunbury and Mandurah) also gives people the option to drive and obtain easily the goods and services that are not provided or are too expensive locally.

On the one hand, mining is blamed for the overall scarcity of human resources in Boddington, but on the other some locals believe that the community does not effectively capitalise on emerging opportunities evoked by its presence:

"No offence to the mining industry in Boddington. It is the slow local population that is not taking full advantage of their presence. If they did, a good legacy could be left when the mine finally leaves." (local resident)

The survey data also revealed that the entrepreneurial spirit within the community is quite low. Close to $80 \%$ of the participants reported that they have never thought about or considered carrying out any entrepreneurial activities. Only less than $10 \%$ indicated that they have thought about starting a business.

Mining in Boddington has become the major contributor to local economic capital. It provides local employment, opportunities for regional growth and potentially for local businesses. The presence of mining also furthers population growth which is expected to result in more viable economic community. However, mining appropriates most available 
human resources, which to a certain extent impedes further community development and prevents capitalisation on available opportunities.

The unfavourable impacts of mining on the local business environment and the recent decline in social capital combined with the transient workforce could potentially be a serious threat to the local community, impacting on its sense of place and culture.

\section{Dependency culture}

The advent of a large mining operation is often envisaged by local communities as an opportunity to provide resources and infrastructure as well as to improve the quality of life and living standards (Auty, 1998; Frynas, 2005; Jenkins \& Obara, 2006). Auty (1998) argues that this type of expectations hides the risk of increasing community dependence on depleting assets, which according to him is an unsustainable process. A dependency culture/mentality emerging in communities dealing with extractive industries in developing countries has been previously described (Frynas, 2005; Ite, 2005). It has been associated with companies' corporate social responsibility (CSR) practices and the provision of local infrastructure. This phenomenon has received minimum attention in developed countries, such as Australia where the dependency culture is as emblematic.

There is a fine line between developing infrastructure related dependency, which is linked to physical resources that a community is not in a position to establish, and the emergence of a dependency mentality on a societal level. The latter translates into unrealistically high social expectations related to the mining industry.

The theme about "dependency" on the mining industry in the Boddington case study was first identified by a local government official:

"The mentality "the company will provide it for us' starts to appear. There are lots of people who worked in other mining operations mainly in towns entirely owned by the company, they are used to lots of facilities and services, which the shire of Boddington cannot provide".

The expectations about what mining should be providing to the local community have significantly risen with the large-scale mine operation. Residents have become a lot more demanding and are more likely to rely on mining rather than government and themselves for improving the quality of life within their community. 
The results from the survey revealed that provision of jobs, supporting community events, other initiatives and improvement of infrastructure appear to be the areas about which community members rely largely on mining and underestimate the role of government (see figure 4). Even though the majority of the respondents (44\%) work in the mining industry, there is no statistically significant correlation between industry field of employment and degree of reliance on mining.

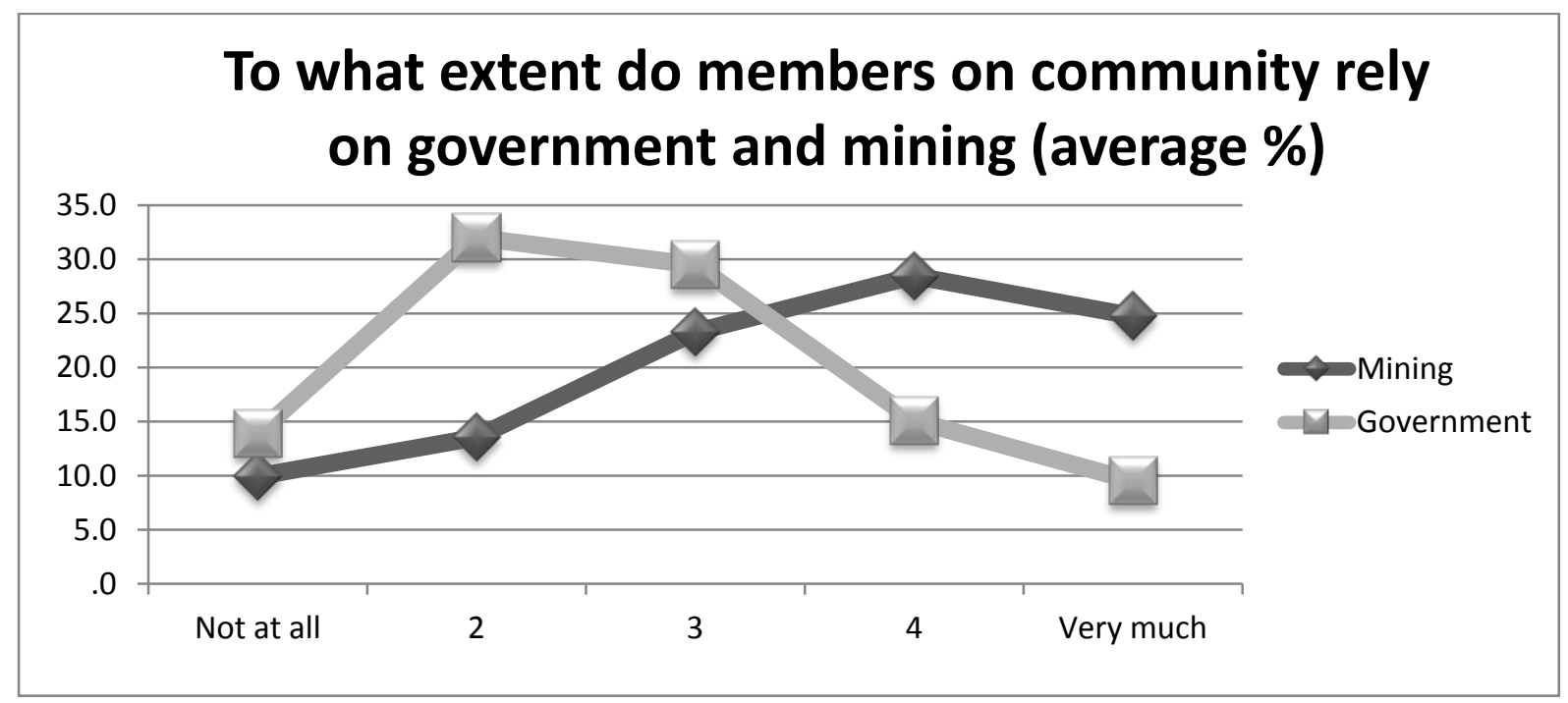

Figure 4 Reliance on government and mining: Boddington

Source: Community survey

Higher expectations about the contribution of the mining industry were also observed during the interviews with local informants:

"...for what comes out of the ground and what goes into the community this is nothing. .... They should provide more money to the community, they should allocate bigger budget, have less constraints and assure more in-kind contribution.... ... mine is horrible with that; they act as if they are giving money out of their personal pockets."

The expectations that companies 'owe' to the community and the associated reliance in relation to social and economic capital hinder the community's initiative, an impediment likely to impact negatively on its long-term social sustainability. 


\section{Conclusion}

The social impacts of mining are not simply negative or positive; they are always interrelated, mutually dependent, cumulative and synergistic (Franks et al., 2011; Vanclay, 2002). This exploratory case study revealed the emergence of two phenomena influenced by the presence of mining, namely: (1) transiency; and (2) dependency culture.

They are both closely associated with the dynamics within the local community. While the response to the second phenomenon could be the development of specific coping mechanisms through community 'owned' strategies, the first phenomenon poses much larger challenges to Boddington, Western Australia and Australia. It includes personal choices and individual lifestyle strategies which require a more in-depth and serious attention. It also raises questions, such as: do we just accept this new culture or do we challenge the existing concept of community to allow for a different approach to planning and mitigating for the social impacts of mining?

Social sustainability is about change. The biggest challenge the Boddington community faces is how to mobilise its own resources and mechanisms in order to respond to the two new phenomena as part of the changing social landscape triggered by mining.

\section{Acknowledgements}

The authors are thankful to the Editor of this Special Issue and two anonymous referees for their helpful comments which improved the quality of the manuscript. They also acknowledge the assistance of Dr Roman Trubka in creating the map of Western Australian locations mentioned in the paper.

\section{References}

Australian Bureau of Statistics (ABS) (2006). Community profiles. Retrieved from http://www.abs.gov.au/AUSSTATS/abs@.nsf/productsbyCatalogue/974A1A5E73830E9A CA2570D90018BFB0?OpenDocument

Australian Bureau of Statistics (ABS) (2010). Labour Mobility Survey. Retrieved from http://www.abs.gov.au

Australian Bureau of Statistics (ABS) (2011). National regional profile: Boddington (S) (Local Government Area). Retrieved from http://www.abs.gov.au 
Australian Bureau of Statistics (ABS) (2012a). Community profiles. Retrieved from http://www.abs.gov.au/websitedbs/censushome.nsf/home/data?opendocument\#frombanner=LN

Australian Bureau of Statistics (ABS) (2012b). QuickStats. Retrieved from http://www.abs.gov.au/websitedbs/censushome.nsf/home/data?opendocument\#frombanner=LN 9

Auty, R.M. (1998). Social sustainability in mineral-driven development. Journal of International Development, 10(4), 487-500

Barron, L., \& Gauntlett, E. (2002). Housing and sustainable communities indicators project. Stage 1 report: model of social sustainability. Perth: WACOSS

Beach, R., Brereton, D., \& Cliff, D. (2003). Workforce turnover in FIFO mining operations in Australia: An exploratory study. Brisbane: University of Queensland

Becker, E., Jahn, T., Stiess, I., \& Wehling, P. (1997). Sustainability: A cross-disciplinary concept of social transformations. Paris: UNESCO

Boddington-Ranford Town-site Strategy (2010). Retrieved from http://www.boddington.wa.gov.au/publications/planning/bodran/bodran/file/at_download

Bourdieu, P. (1986). The forms of capital. In J. Richardson (Ed.) Handbook of theory and research for the sociology of education (pp. 241-258). New York, Greenwood

Boxill, I., Chambers, C., \& Wint, E. (1997). Introduction to social research with applications to the Caribbean. The University of the West Indies Press. Kingston.

Brereton, D., \& Pattenden, C. (2007). Measuring what matters: monitoring the contribution of a new mining project to community sustainability. 3rd international conference on sustainable development indicators in the mining industry. Milos Island, Greece.

Carrington, K., \& Pereira, M. (2011). Assessing the social impacts of the resources boom on rural communities. Rural Society, 21(1), 2-20. Retrieved from http://dx.doi.org/10.5172/rsj.2011.21.1.2. doi:10.5172/rsj.2011.21.1.2

Cheshire, L., Everingham, J.-A., \& Pattenden, C. (2011). Examining corporate-sector involvement in the governance of selected mining-intensive regions in Australia. Australian Geographer, 42(2), 123-138. $\quad$ Retrieved from http://dx.doi.org/10.1080/00049182.2011.569986. doi:10.1080/00049182.2011.569986

Coleman, J. S. (1988). Social capital in the creation of human capital. American Journal of Sociology, 94, S95-S120. Retrieved from http://www.jstor.org/stable/2780243 
Dempsey, N., Bramley, G., Power, S., \& Brown, C. (2011). The social dimension of sustainable development: Defining urban social sustainability. Sustainable Development, 19(5), 289-300. Retrieved from http://dx.doi.org/10.1002/sd.417. doi:10.1002/sd.417

Department of Immigration and Citizenship (2011). Population distribution effects of migration in Australia. Research Report. Retrieved from http://www.immi.gov.au/media/publications/research/migration-in-australia/

Esteves, A. M. (2008). Mining and social development: Refocusing community investment using multi-criteria decision analysis. Resources Policy, 33(1), 39-47. Retrieved from http://www.sciencedirect.com/science/article/B6VBM-4RV7H0C1/2/33f00f31d1ab59e60eb5527ddbf3a857

Evans, R., Brereton, D., \& Joy, J. (2007). Risk assessment as a tool to explore sustainable development issues: lessons from the Australian coal industry. International Journal of Risk Assessment and Management, 7, 607-619. Retrieved from http://www.ingentaconnect.com/content/ind/ijram/2007/00000007/00000005/art00002

Forsey, M. (2011). Living on the edge: Supplementing education in an Australian mining town. The Focus: Supplementary Education in Asia, 56, 21-23.

Franks, D. (2012). Social impact assessment of resource projects. International Mining for Development Centre. Retrieved from http://im4dc.org/wpcontent/uploads/2012/01/UWA_1698_Paper-02_Social-impact-assessment-of-resourceprojects1.pdf

Franks, D., Fidler, C., Brereton, D., Vanclay, F. \& Clark, P. (2009). Leading practice strategies for addressing the social impacts of resource developments. Retrieved from http://www.csrm.uq.edu.au/docs/Franks_etal_LeadingPracticeSocialImpacts_2009.pdf

Franks, D. M., Brereton, D., Moran, C. (2011). Cumulative social impacts. In F. Vanclay \& A.M. Esteves (Eds) New directions in social impact assessment: Conceptual and methodological advances (pp. 202-220 ). Cheltenham: Edward Elgar.

Freudenburg, W.R. (1986). Social impact assessment. Annual Review of Sociology, 12(1), 451.

Retrieved

from

http://sfx.lis.curtin.edu.au/sfx_local?sid=google\&auinit=WR\&aulast=Freudenburg\&atitle $=$ Social $\% 20 \mathrm{impact} \% 20$ assessment $\& \mathrm{id}=\mathrm{doi} \% 3 \mathrm{~A} 10.1146 \% 2$ Fannurev.so.12.080186.00231 5

Frynas, J. G. (2005). The false developmental promise of Corporate Social Responsibility: evidence from multinational oil companies. International Affairs, 81(3), 581-598. 
Government of Western Australia. (2011). Western Australian mineral and petroleum statistic digest 2010-11. Perth.

Gravetter, F.J., \& Forzano, L.A.B. (2008). Research methods for the behavioral sciences, (3rd edition), Belmont, CA: Wadsworth/Cengage Learning.

Hajkowicz, S. A., Heyenga, S., \& Moffat, K. (2011). The relationship between mining and socio-economic well being in Australia's regions. Resources Policy, 36(1), 30-38. Retrieved from http://www.sciencedirect.com/science/article/B6VBM-511KB8N1/2/c612fa61a7f0afc9bf6ee533e379c872. doi:DOI: 10.1016/j.resourpol.2010.08.007

Howitt, R. (2001). Rethinking resource management: Justice, sustainability and indigenous peoples. London: Routledge.

Ite, U. E. (2005). Poverty reduction in resource-rich developing countries: what have multinational corporations got to do with it? Journal of International Development, 17(7), 913-929

Jenkins, H., \& Obara LJ. (2006). Corporate social responsibility in the mining industry - the risk of community dependency. The Corporate Responsibility Research Conference. Dublin.

Kay, P.J., Blewett, R.S., \& Huston, D.L. (2012). Sustaining Australia's wealth - economic growth from a stable base. In R.S. Blewett (Ed.), Shaping a Nation: A Geology of Australia (pp. 433-481). Canberra: ANU ePress with Geoscience Australia.

Lawrie, M., Tonts, M., \& Plummer, P. (2011). Boomtowns, resource dependence and socioeconomic well-being. Australian Geographer, 42(2), 139-164. Retrieved from http://dx.doi.org/10.1080/00049182.2011.569985

Lister, R. (2000). Strategies for social inclusion: promoting social cohesion or social justice? In Askonas \& S. A. P (Eds) Social inclusion: Possibilities and tensions (pp. 37-54). Basingstoke: Macmillan.

Lockie, S., Franettovich, M., Petkova-Timmer, V., Rolfe, J., \& Ivanova, G. (2009). Coal mining and the resource community cycle: A longitudinal assessment of the social impacts of the Coppabella coal mine. Environmental Impact Assessment Review, 29(5), 330-339. Retrieved from http://www.sciencedirect.com/science/article/B6V9G-4VT0GVM1/2/f0908510ad5df021ed346cebbb0746ce

Lozeva, S.. \& Marinova, D. (2010). Negotiating Gender: Experience from Western Australian Mining Industry. Journal of Economic and Social Policy, 13(2), 177-209. Retrieved from http://epubs.scu.edu.au/jesp/vol13/iss2/7 
McKenzie, F.M.H. (2009). Farms and mines: a conflicting or complimentary land use dilemma in Western Australia? Journal for Geography, 4(2), 113-128. doi:http://www.ff.uni-mb.si/zalozba-in-knjigarna/ponudba/zbirke-in-revije/revija-zageografijo/clanki/stevilka-4-2-2009/042-10_haslam_mckenzie.pdf

McKenzie, F.H. (2011). Fly-in fly-out: the challenges of transient populations in rural landscapes. In G.W. Luck, D. Race \& R. Black (Eds) Demographic change in Australia's rural landscapes: Implications for society and the environment (pp. 353-374). Merlbourne: CSIRO.

McKenzie, F.H., Brereton, D., Birdsall-Jones, C., Phillips, R., \& Rowley, S. (2008). A review of the contextual issues regarding housing market dynamics in resource boom towns. Melbourne: Australian Housing and Urban Research Institute

McKenzie, S. (2004). Social sustainability: Towards some deffinitions. Working Paper Series N27. Adelaide: University of South Australia

O'Faircheallaigh, C. (2009). Effectiveness in social impact assessment: Aboriginal peoples and resource development in Australia. Impact Assessment and Project Appraisal, 27, 95110. Retrieved from http://www.ingentaconnect.com/content/beech/iapa/2009/00000027/00000002/art00002

O'Connor, K., \& Kershaw, L. (1999). Outsourcing, producer services and shifts in the geography of the Australian mining industry. Australasian Journal of Regional Studies, $5(1), 73-86$.

Petkova-Timmer, V., Lockie, S., Rolfe, J., \& Ivanova, G. (2009). Mining developments and social impacts on communities: Bowen Basin case studies. Rural Society, 19(3), 211-228. Retrieved from http://pubs.e-contentmanagement.com/doi/abs/10.5172/rsj.19.3.211. doi:10.5172/rsj.19.3.211

Petrova, S. (2012). Social impacts of mining: a Western Australian community case study, (Forthcoming PhD thesis). Curtin University, Perth, Australia.

Pini, B., Previte, J., \& McKenzie, F.H. (2007). Stakeholders, natural resource management and Australian rural local governments: a $\mathrm{Q}$ methodological study. Local Government Studies, 33(3), 427-449. Retrieved from http://dx.doi.org/10.1080/03003930701289638

Putnam, R. D. (2001). Bowling alone: The collapse and revival of American community. New York: Simon and Schuster

Rolfe, J., Petkova,V., Lockie, S. \& Ivanova, G. (2007). Mining impacts and the development of the Moranbah township. Canberra: Australian National University 
Stehlik, D., Browne, A.L., \& Buckley, A. (2011). The contribution of rapid rural appraisal techniques to social impact assessment: the case of Ravensthorpe, Western Australia. In J. Rolfe, S. Lockie, \& G. Ivanova (Eds) Advances in social and economic impact assessment of mining activities. Canberra: ANU E Press. Retrieved from http://eprints.lancs.ac.uk/40914/1/Book_Lockie_Rolfe_ANU_RRR.pdf

Storey, K. (2001). Fly-in/Fly-out and Fly-over: Mining and regional development in Western Australia. Australian Geographer, 32(2), 133-148. Retrieved from http://dx.doi.org/10.1080/00049180120066616. doi:10.1080/00049180120066616

Tashakkori, A., \& Teddlie, C. (2003). Handbook of mixed methods in social and behavioral research. London: SAGE.

Tonts, M. (2010). Labour market dynamics in resource dependent regions: an examination of the Western Australian Goldfields. Geographical Research, 48(2), 148-165. Retrieved from http://dx.doi.org/10.1111/j.1745-5871.2009.00624.x

Tonts, M., Plummer, P., \& Lawrie, M. (2011). Socio-economic wellbeing in Australian mining towns: A comparative analysis. Journal of Rural Studies. Retrieved from http://www.sciencedirect.com/science/article/pii/S0743016711000933

Vanclay, F. (2002). Conceptualizing social impacts. Environmental Impact Assessment Review, 22(3), 183-211 